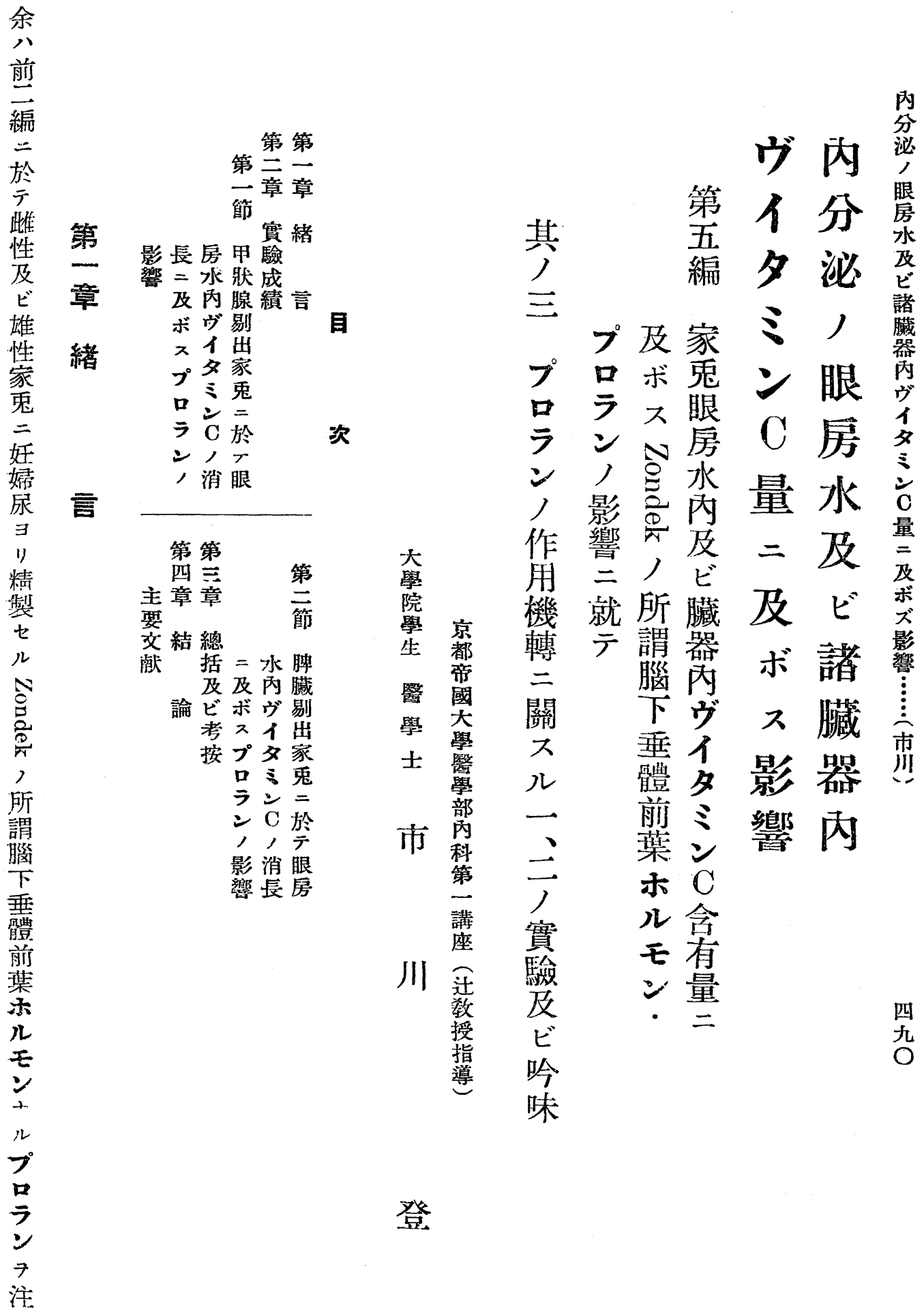




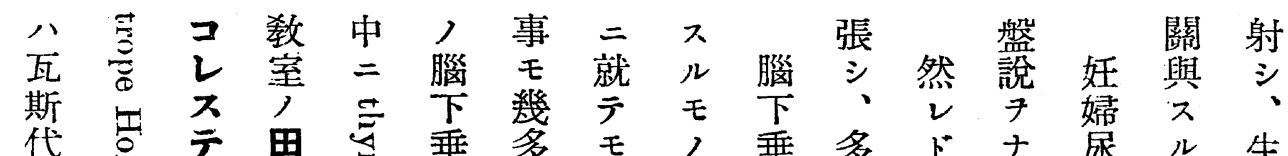

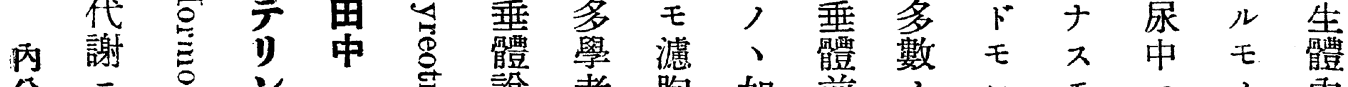

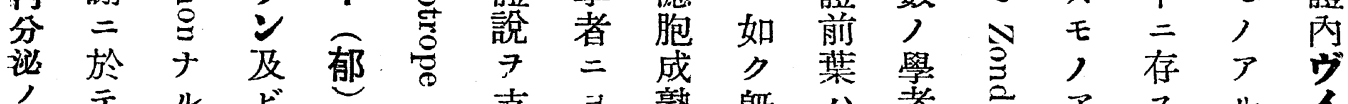
眼 林 事 カ 八。 可持

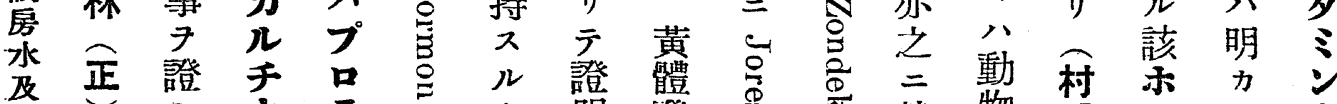
及正證 チ ロ

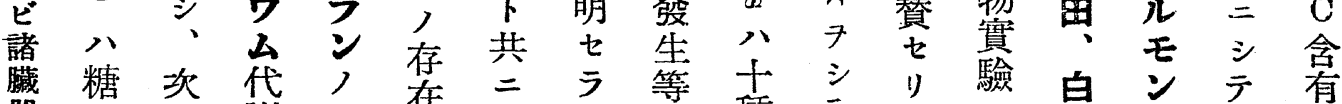

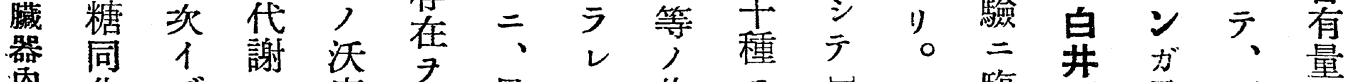

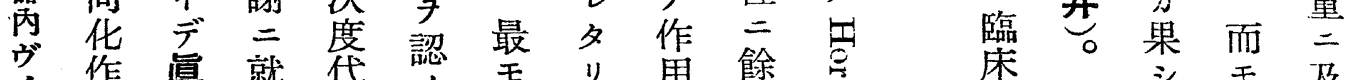

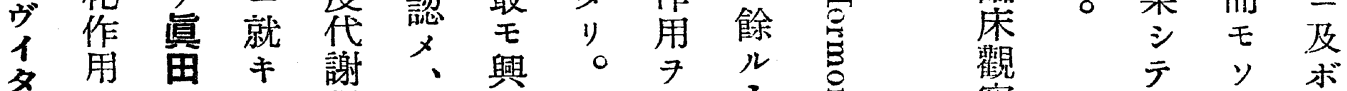

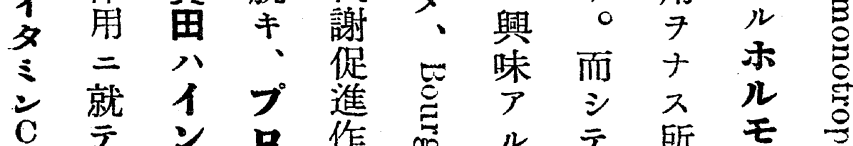
量何手方用及所斯謂シ

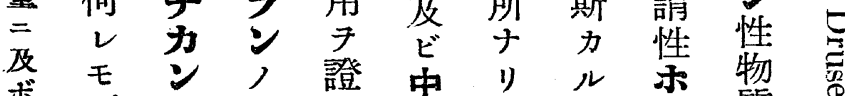

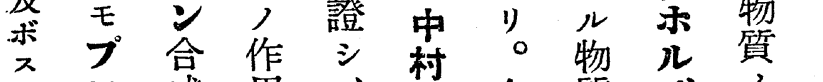

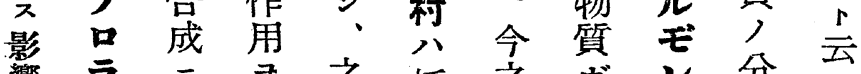

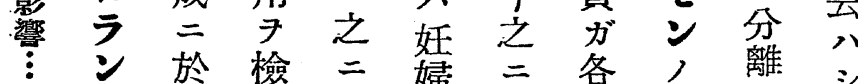

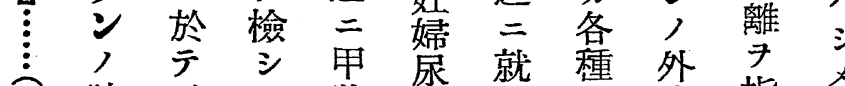

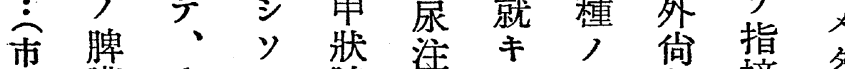
川藏 小愽腺射少內 各摘

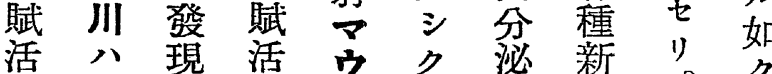
性血二性 万文腺陳。ク チ獎心ナ及献卜代冬各 主及脾りり゙ョ 密謝所種 張ビ臟ト白溫接二謂內 七膽了論鼠邓竞腦分

四 沓在 リ

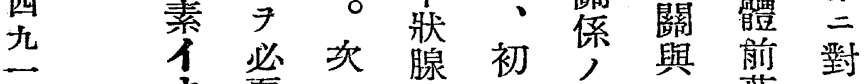
才要二組 メ間不葉

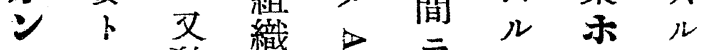

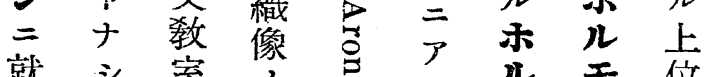
就 シ 窒, Ð ルル壬位 キ 即当變 健事モモン香 テ、チ草變健 事・ン・ル 又䟥少登人康 心

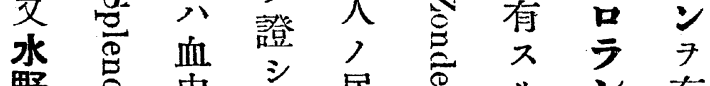

察

二 䪿作 影

又體少

組 二 性 檢 織基 腺 七 學源 7 り

的 $介$ 个。 二ル シ 而 或 否 主 生尣次其 化 其 二 成 學了發 績 的 證 現 $\exists$ 二 明 幾甚 ル 見 多多モし 根禁, 唯 據薙 云

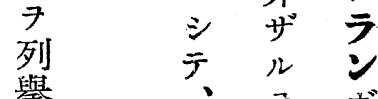
擧 、テ ガ

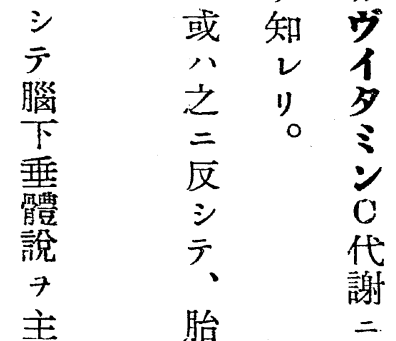




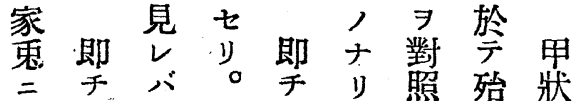
プ實虫最虫望眿

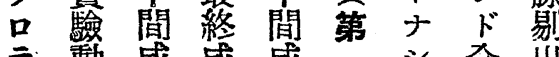
今動成盛盛二シ全出

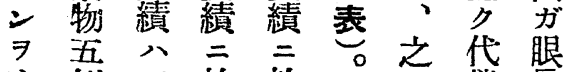
注例言於於。之償房

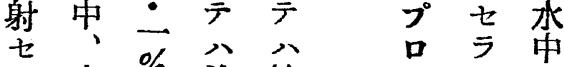

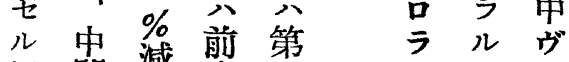
場閔減著例方名

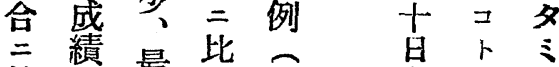

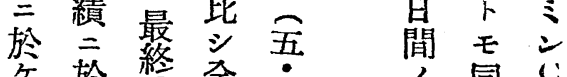

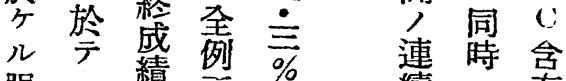
朖八績烈\% 續

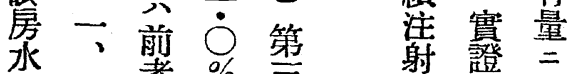
离者草方

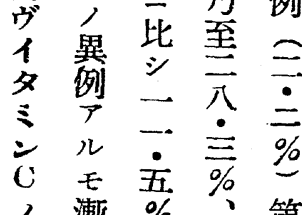
渻輱 \% 對第 長分對照 例 比咕照前无

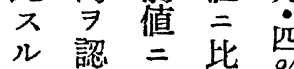

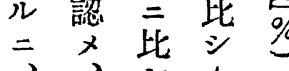
确最光溜

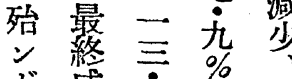

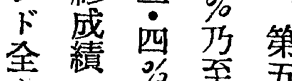

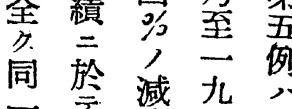

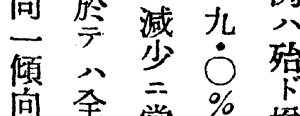

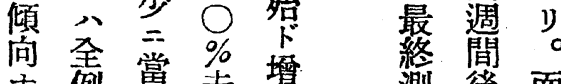

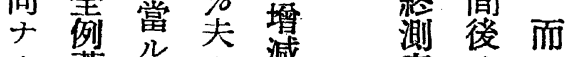

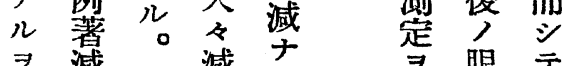
$\exists$ 堿 減 知安少、諼,

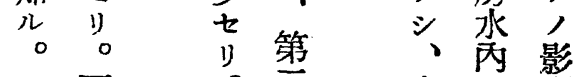

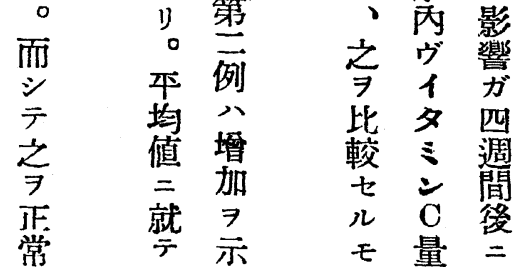

行㤂书

七 $\Rightarrow$ 不

皆影

ソテ、镜

間 本 就

第實玄

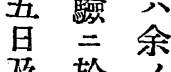

范於前

第公論

盛交

人蒙於

回甯報

二牀 整

及出 所
成討 卜

精 7 借 八明 厂

大八前

要虽二 二

然 $t$ 蹁永

表ナル，泌

示 七责以余眼

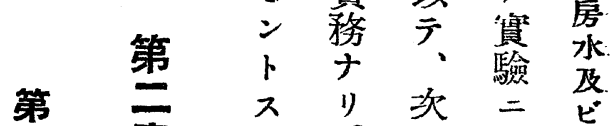

筐

及甲 實

㷊牀驗

䇰出成

間腺 れ

家

ん㮔 績

眼

影 房

水

芮

w

た

み

G

龺

即 デ热 諸

许集丙
于, 占器

機

驗 轉 シ

立關帒竞

人謝 量

如 呚 三 =

キ室關㤂

成 先 與

績 輩 ス 影

フコ ル婂

得 跡 70

多做 只市

實可 背

驗甲作

方 狀 用

法腺 八

二 亚 性

就 = 腺

テ脾 7

八藏介

朁 剔 ス

$=$ 出

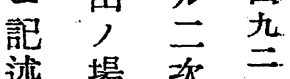

了合 的

り

詳於果

䢞少二

$7 ル$

避 影 ラ

響 ザ

實 7 


\begin{tabular}{|c|c|c|c|c|c|c|}
\hline 家鬼番號 & 性 & $\begin{array}{c}\text { 體 重 } \\
\text { (瓦) }\end{array}$ & $\begin{array}{c}\text { 前 試 驗 } \\
\text { (甲狀腺剔出四後) } \\
(\text { 娫/距) }\end{array}$ & \multirow{7}{*}{$\begin{array}{c}\text { プ } \\
\mathbf{p} \\
\text { ラ } \\
\text { ン } \\
+ \\
\text { 日 } \\
\text { 間 } \\
\text { 連 } \\
\text { 續 } \\
\text { 注 } \\
\text { 射 }\end{array}$} & $\begin{array}{l}\text { 五日後 } \\
\text { (珽/站) }\end{array}$ & $\begin{array}{l}\text { 十日 後 } \\
\text { (酕/证) }\end{array}$ \\
\hline 1 & $\hat{o}$ & 1990 & $\begin{array}{ll}\text { 左 } & 0.185 \\
\text { 右 } & 0.185\end{array}$ & & 左 0.175 & 右 0.156 \\
\hline 2 & $\delta$ & 2120 & $\begin{array}{ll}\text { 左 } & 0.100 \\
\text { 右 } & 0.100\end{array}$ & & tr. 0.113 & 右 0.081 \\
\hline 3 & $\delta$ & 1890 & $\begin{array}{ll}\text { 左 } & 0.135 \\
\text { 右 } & 0.137\end{array}$ & & 左 0.133 & 右 0.126 \\
\hline 4 & $\delta$ & 2000 & $\begin{array}{ll}\text { 左 } & 0.160 \\
\text { 右 } & 0.158\end{array}$ & & 左 0.144 & 右 0.141 \\
\hline 5 & $\delta$ & 1920 & $\begin{array}{ll}\text { 左. } & 0.130 \\
\text { 右 } & 0.131\end{array}$ & & tr. 0.132 & 右 0.112 \\
\hline 平. 均 & & & 0.142 & & 0.339 & 0.123 \\
\hline & & & 苐 & & & \\
\hline \begin{tabular}{|l} 
家鬼番號 \\
\end{tabular} & 性 & $\begin{array}{c}\text { 體 重 } \\
\text { （瓦） }\end{array}$ & 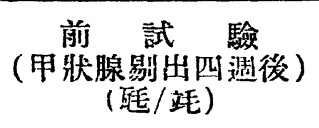 & & $\begin{array}{l}\text { 五日 後 } \\
\text { (醜/洭) }\end{array}$ & $\begin{array}{l}\text { 十日渃 } \\
\text { (配/靖) }\end{array}$ \\
\hline 1 & $\delta$ & 2190 & $\begin{array}{ll}\text { 左 } & 0.110 \\
\text { 右 } & 0.115\end{array}$ & $\begin{array}{l}7^{\circ} \\
\square\end{array}$ & 左 0.111 & 右 0.108 \\
\hline 2 & $\delta$ & 2000 & $\begin{array}{ll}\text { 左 } & 0.106 \\
\text { 右 } & 0.113\end{array}$ & $\begin{array}{l}\text { ラ } \\
\text { ン }\end{array}$ & 左 0.105 & 右 0.105 \\
\hline 3 & $\delta$ & 1800 & $\begin{array}{ll}\text { 左 } & 0.122 \\
\text { 右 } & 0.125\end{array}$ & 間 & 左 0.126 & 右 0.124 \\
\hline 4 & $\delta$ & 2110 & $\begin{array}{ll}\text { 左 } & 0.165 \\
\text { 右 } & 0.166\end{array}$ & $\begin{array}{l}\text { 連 } \\
\text { 續 }\end{array}$ & 左 0.161 & 右 0.169 \\
\hline 5 & $\delta$ & 2200 & $\begin{array}{ll}\text { 左 } & 0.132 \\
\text { 右 } & 0.134\end{array}$ & $\begin{array}{l}\text { 讷 } \\
\text { 射 }\end{array}$ & 灰 0.135 & 右 0.130 \\
\hline 平均 & & & 0.127 & & 0.126 & 0.127 \\
\hline
\end{tabular}


次進 ハ 㒂賦 即 殆 以

網 コ 眼 脾 性 ヴ 全 三

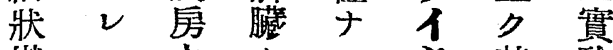

織二水卜ルタ其驗

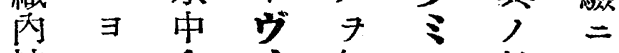

被 含 1 知

細一有タルささ妇リ

胞般占令。代—市

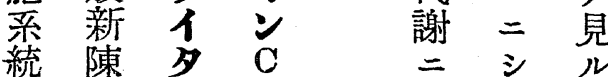

代亦代闒 シ

尚謝 $ン$ 謝與 脾 生

$1>\mathrm{C} \quad \mathrm{r}$

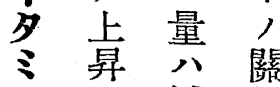

父減係

$\mathrm{C}$ 主 少 二

代 因 ス 就

謝 夕 0 テ

二小而八

就 今゙ シ 余

テキテノ

八コ 前

川容了論

瀨易減文

並推少 詳

川知脾 述

ノ 七藏 ス

實

驗 ル最所

ア ソ モ

リ所密り

氏

等 ○ シ 㐫

二 及

$\exists$ 拮 ビ

抗 余

バ關俞

问 係實

系 二 驗

統 $\boldsymbol{\gamma}$

失年於

調甲 テ

$=$ 狀 脾

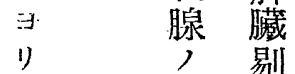

$\begin{array}{lll}\text { 眼 穖 } & \text { 出 } \\ \text { 房 能 } & 7\end{array}$
ス 藏 體

ル 剔內

口 1

場

$\checkmark$ 合 :

作 $=\frac{Y}{\mathrm{C}}$

用其代

八ノ謝

草作 二

野用及

ヨノボ

始發 ス

氣現 ブ

田見 ジ

小准

川! 作

其 分

他午狀

敎腺

室剔

數出

氏 家

實 二

於

= テ

見、

$\begin{array}{ll}\text { 如 } & \text { 正 } \\ \text { 常 } \\ \text { 脾 }\end{array}$

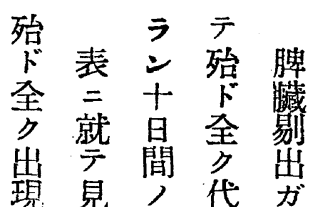

セ兄連償眼

ズ二續セ房

實射 拄

第簽 录

物 ᄂ r 文

覃

總

テソ同 它

中分時 C

括

及

ビ

閪䦐 含

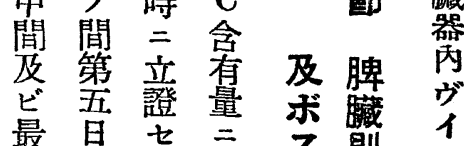

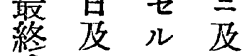

威 ビ 录

績 第 以

於日 成 響

按

テ人熟掏

慬 回萣 就

示前 而

䶍間藏余

減 品出 論

儿最週艾

今終閴立

ナ定 壬

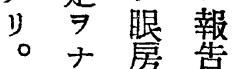

即 亦 水

チ脾学离所

藏此 $11 \%$

出 䡆名り

家リ方而

香第量

於第量

テ表嚉 影

プ

ラ

ナ猎

シ 竏

之 閏

二 後

口於

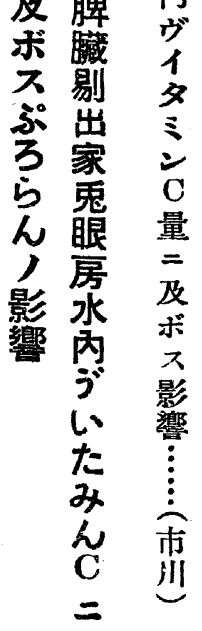

四

見 


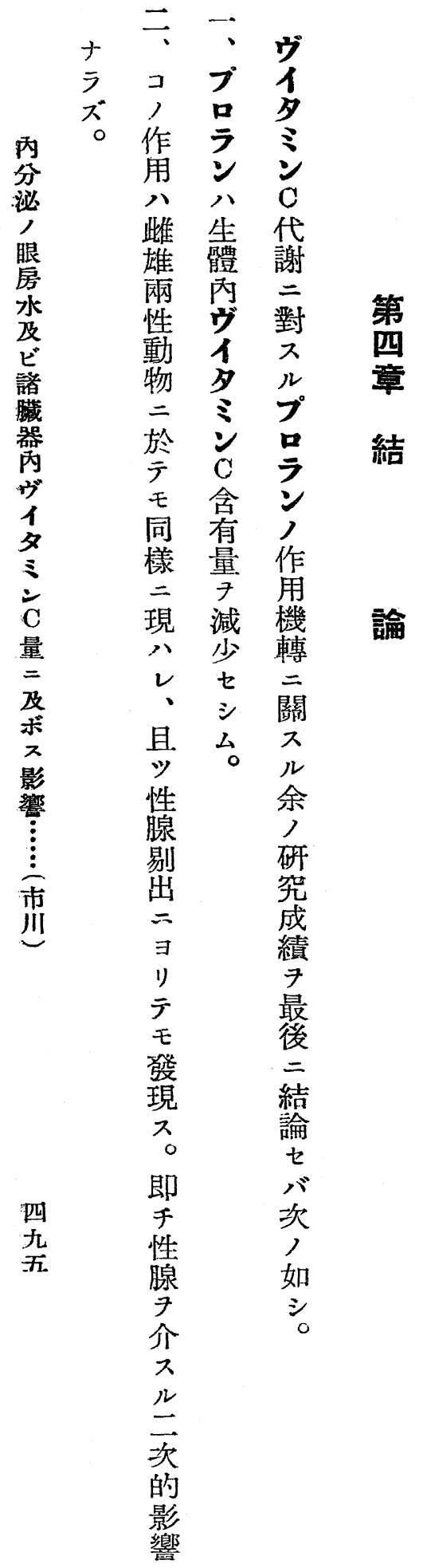

当而余コ血急浞脤二水 一 シ 實 $レ 二$ 攝 致 ラ 䖍 等 注 取 $\exists$ 網、有 スコニ諸入機ル狀脾号 ル了見蒙サ能網織贜

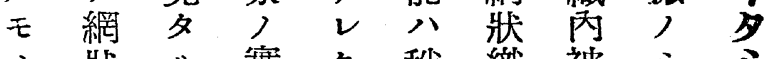
, 狀儿實タ稍織被之主

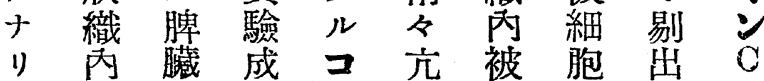

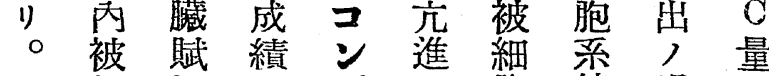
細 活 $\exists \exists$ 胞統場 胞性り、ル系卜合增 系ナ考口ヲ 統, 只加 統 ル察 】認機間八チ

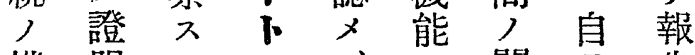
機明ル,、關亏告 能 $卜$ = 攝成檢係異 七 充軌妊取松 三三ルル 進 尹 娠作 モ 就モ ガ 二同尿用亦其 $\neq$, $\exists シ ゙$ 防即妊 $>$ 興アコ リク至于娠機味》レ テ フ 網厡能卢卢 體 ルロ狀製艺ル信廣 內モラ 織 劑進實 ぜ 沉

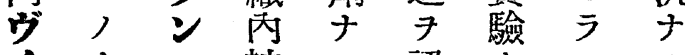

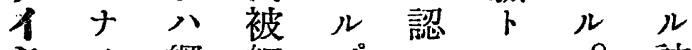
タリ網 細 プメ、シ。該 令牀胞 ᄂ

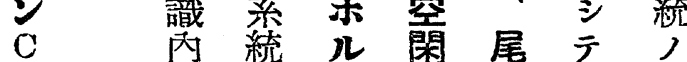
, 被樣モモ池所壃 減細能 $ン$ 同八謂塞 少胞克 7 樣家腦二 系進家娃兔下ア 見 統 $\ni$ 鬼娠二垂

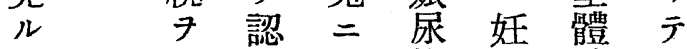

コ 刺 $x$ 連淮娠前 八 $卜$ 战 夕續 射尿葉 其 八 シ 注二尹禾了 鼓。射 $\exists$ 注 $九$ 沙 川 舞 シ リ射モ費 瀨算

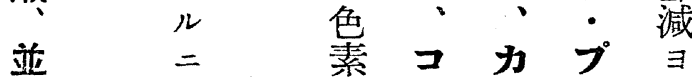
川 等 致 茶 ) 成檢口, 万品

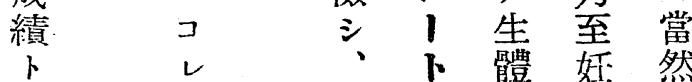




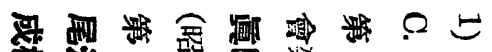

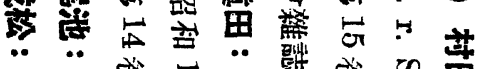

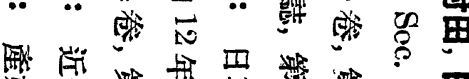

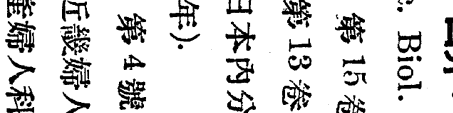

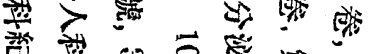

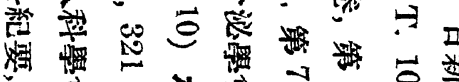

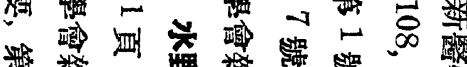

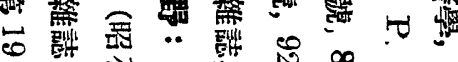

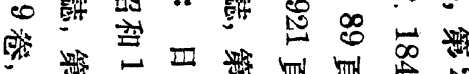

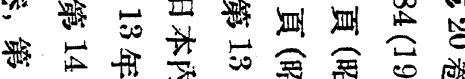

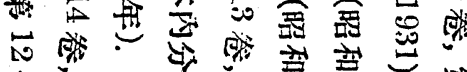

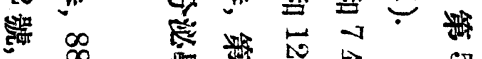

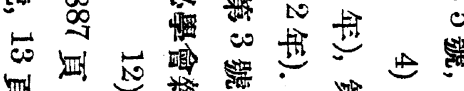

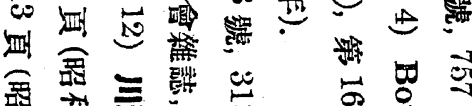

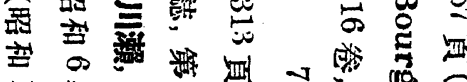

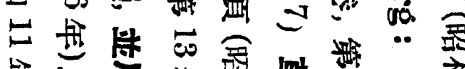

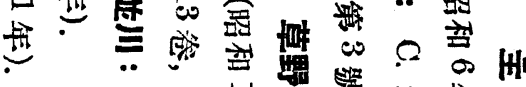

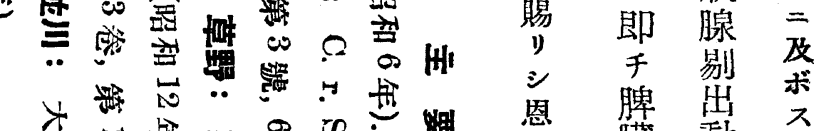

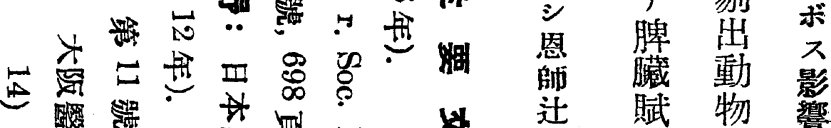

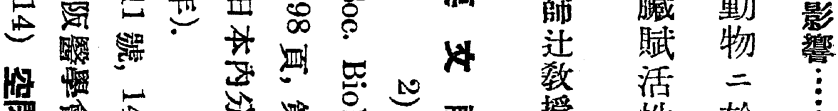

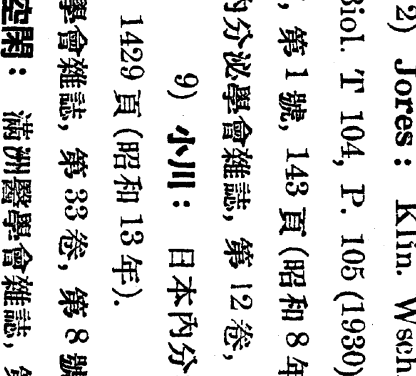

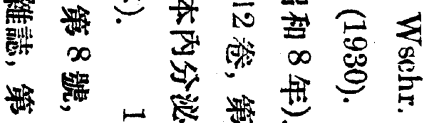

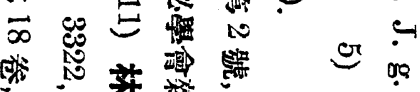

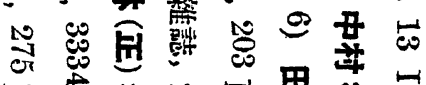

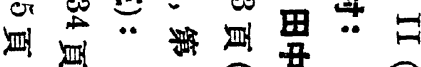

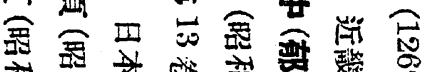

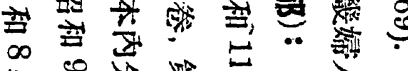

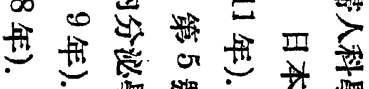

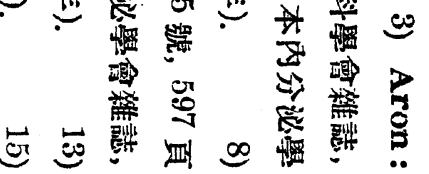

四 三

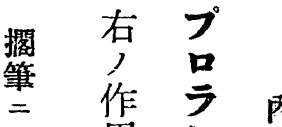

臨用 分

心 八 汹

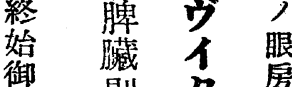

稳剔夕居

馬動 ミ 及

物 $\mathrm{C}$ 諸

御二代塤

指 於謝 器

御發與

閱 現 角

䇰艺公

$\exists 、$ 狀 量

性於

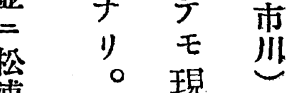

講

媓佂 2

深從

謝兴

テ

甲

狀四

賦 窖

性

ナ 


\title{
Über den Einfluss der Innersekretion auf den Vitamin-C-gehalt des Augenkammerwassers und sonstiger Organe. V. Mitteilung.
} Über das Wesen der Wirkung des Zondekschen „Prolans“.

Von

\author{
Dr. N. Ichikawa.
}

(Aus der 1. Med. Klinik der Kaiserl. Universität zu Kyoto in Japan. Direktor: Prof. Dr. K. Tsuji)

Der Verfasser untersuchte, ob und wie die Exstirpation der Schilddrüse sowie der Milz die Prolanwirkung auf den Vitamin-CUmsatz beeinflusst. Dass der direkte Einfluss der Thyreoidektomie schon 4 Wochen nach der Operation und der der Splenektomie 3 Wochen nach derselben kompensiert werden, wurde bereits festgestellt (s. Verfassers frühere Arbeiten). Deshalb wurde das Prolan den thyreoidektomierten Kaninchen erst 4 Wochen nach der Operation und den splenektomierten 3 Wochen post operationem eingespritzt. Das Prolan wurde täglich einmal injiziert, und zwar 10 Tage lang. Die sonstigen Versuchsanordnungen waren wie in den früheren Versuchen. Die Arbeitsergebnisze lasaen sich wie folgt zusammenfassen.

1) In den Mitteilung I. bis V. findet sich sichergestellt, dass das Prolan den Vitamin-C-gehalt des Körpers vermindert.

2) Diese Wirkung des Prolans auf den Vitamin-C-umsatz tritt bei weiblichen ebensowie bei männlichen Tieren zutage, auch bei kastrierten. Daraus folgt, dass es sich bei dieser Prolanwirkung um keine sekundäre Wirkung via Keimdrüsen handelt.

3) Die Wirkung des Prolans auf den Vitamin-C-umsatz zeigt sich auch bei thyreoidektomierten 'Tieren, sie bedarf also keiner Vermittlung der Schilddrüse.

4) Die Wirkung des Prolans auf den Vitamin-C-umsatz bleibt bei splenektomierten Tieren aus, ist also splenotroper Natur.

(Autoreferat) 